Mr Boban Bondžulić, kapetan, dipl. inž.

Vojna akademija - Odsek logistike, Beograd

dr Žarko Barbarić dipl. inž.

Elektrotehnički fakultet,
Beograd

\section{JEDAN PRISTUP DETEKCIJI POKRETA NA SLICI SCENE}

UDC: 77.034

Rezime:

U ovom radu opisan je jedan pristup koji se primenjuje u detekciji pokreta. Naime, koristi se obrada slike razlike formirane oduzimanjem slike pozadine od tekućeg frejma i oduzimanjem sukcesivnih frejmova. Zbog nedostataka koji se javljaju ukoliko se koriste tehnike oduzimanja slike pozadine i oduzimanja sukcesivnih frejmova, opisan je i kombinovani metod detekcije. Ovaj metod predstavlja spoj tehnika oduzimanja sukcesivnih frejmova i oduzimanja slike pozadine. Kako je za detekciju pokreta potrebna slika pozadine, opisan je jedan od postupaka izdvajanja slike pozadine.

Ključne reči: detekcija pokreta, slika pozadine, oduzimanje slike pozadine, oduzimanje sukcesivnih frejmova, kombinovani metod detekcije.

\title{
ONE APPROACH TO MOVEMENT DETECTION ON IMAGE
}

Summary:

In this paper the approach for movement detection is described. The approach is based on background subtraction and temporal differencing. To overcome problems with these two techniques, a hybrid algorithm for change detection is described. A hybrid algorithm is a combination background subtraction technique with a frame differencing technique. In this paper the method for background extraction is described, too.

Key words: movement detection, background model, background subtraction, temporal differencing, a hybrid algorithm for change detection.

\section{Uvod}

U nekim primenama digitalne obrade slike postoji potreba da se utvrdi da li je slika mirna ili sadrži pokret. Dve značajne oblasti primene detekcije pokreta su redukcija šuma i kompresija podataka. Potrebno je ne samo da se detektuje prisustvo pokreta na slici, već je neophodno poznavati i njegove parametre, kao što su, na primer, brzina i pravac. Poznavanje ovih parametara je značajno za kompresiju podataka radi prenosa ili memorisanja slike.
Dinamika na slici može da postoji zbog kretanja objekata na sceni, ali i zbog kretanja same kamere ili dejstva optike (zum). Ukoliko postoji istovremeno kretanje i objekta i kamere, onda je rezultantni pokret vektorski zbir ova dva pokreta [1].

Za detekciju pokreta (promena) na slikama scene može se koristiti obrada slike razlike koja se dobija oduzimanjem slike pozadine od tekućeg frejma (background subtraction) ili oduzimanjem sukcesivnih frejmova (temporal differencing). Ova detekcija praćena je uvođe- 
njem praga da bi se dobila binarna slika u kojoj su pikseli klasifikovani u dve klase (pozadina i pokretni piksel). Neki autori navode da je razlog uvođenja praga razdvajanje ove dve klase $[2,3,4,5]$.

\section{Detekcija pokreta oduzimanjem sukcesivnih frejmova}

Označimo sa $I^{n}(x, y)$ vrednost nivoa sivog piksela frejma (slike) na poziciji $(x, y)$ u trenutku $t=t_{n}$. Mera sličnosti dva frejma uzeta $\mathrm{u}$ trenutku $t=t_{n}$ i $t=t_{n-1}$ može se izraziti kao [6, 7]:

$$
\begin{aligned}
& D^{n}(x, y)=\left|I^{n}(x, y)-I^{n-1}(x, y)\right|, \\
& \forall(x, y) \in[1, N] \times[1, M]
\end{aligned}
$$

gde je $N \times M$ dimenzija frejma u pikselima. Na ovaj način (oduzimanje sukcesivnih frejmova) dobija se slika razlike $D^{n}$.

U odsustvu pokreta (promena), u idealnom slučaju iz (1), dobija se:

$$
D^{n}(x, y)=0, \forall(x, y) \in[1, N] \times[1, M]
$$

Ilustracije radi, na slici 1 šematski su prikazana dva ista sukcesivna frejma $\mathrm{i}$ slika razlike.
Uzmimo sada nekoliko sukcesivnih frejmova realne sekvence u kojima ne postoje pokretni objekti. Na slici 2 prikazana su tri sukcesivna frejma i dve slike razlike.

Na slikama razlike $2 b$, pikseli kod kojih nije došlo do promene nivoa sivog prikazani su kao beli, radi boljeg uočavanja (vizuelni efekt). Ostali pikseli kod kojih je došlo do promene nivoa sivog prikazani su nijansama nivoa sivog. Broj piksela na kojima je došlo do promene nivoa sivog je oko $87 \%$ ukupnog broja piksela slike razlike. Pri ovoj analizi nije važan intenzitet promena. Može se zaključiti da su ove promene nastale zbog šuma, pa se (1) može izraziti u formi:

$I^{n}(x, y)=I^{n-1}(x, y)+I_{n}^{n}(x, y)$

gde je $I_{n}^{n}(x, y)$ nivo šuma $\mathrm{u}$ trenutku $t=t_{n}$ na poziciji $(x, y)$. Raspodela nivoa sivog (histogram) slike razlike $D^{3}$, sa slike $2 b$, prikazana je na slici 3 .

Sa slike 3 vidi se da je maksimalna vrednost 30 od mogućih 256 nivoa sivog, a da se najčešće javljaju nivoi $0 \leq i \leq 10$. Vrednost 0 odgovara crnom, a vrednost 255 belom nivou.

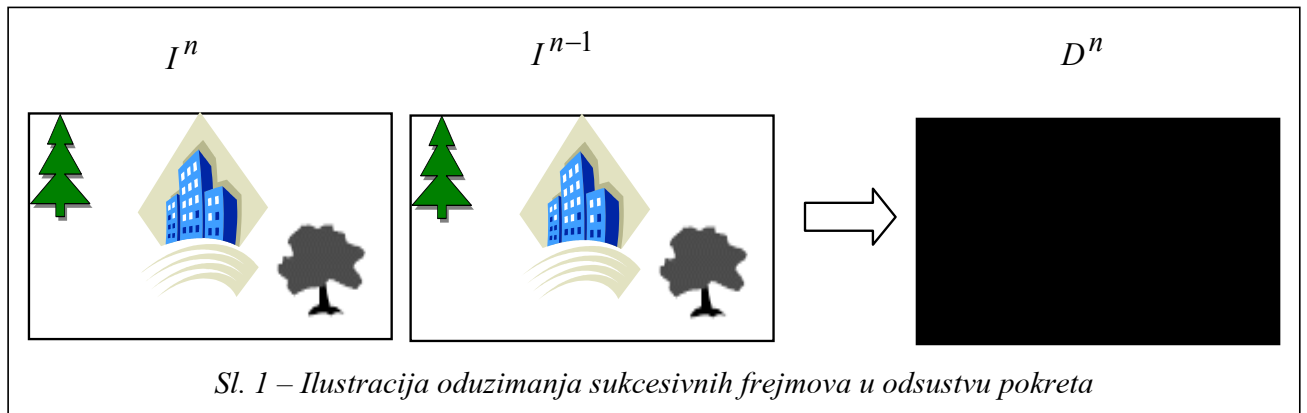




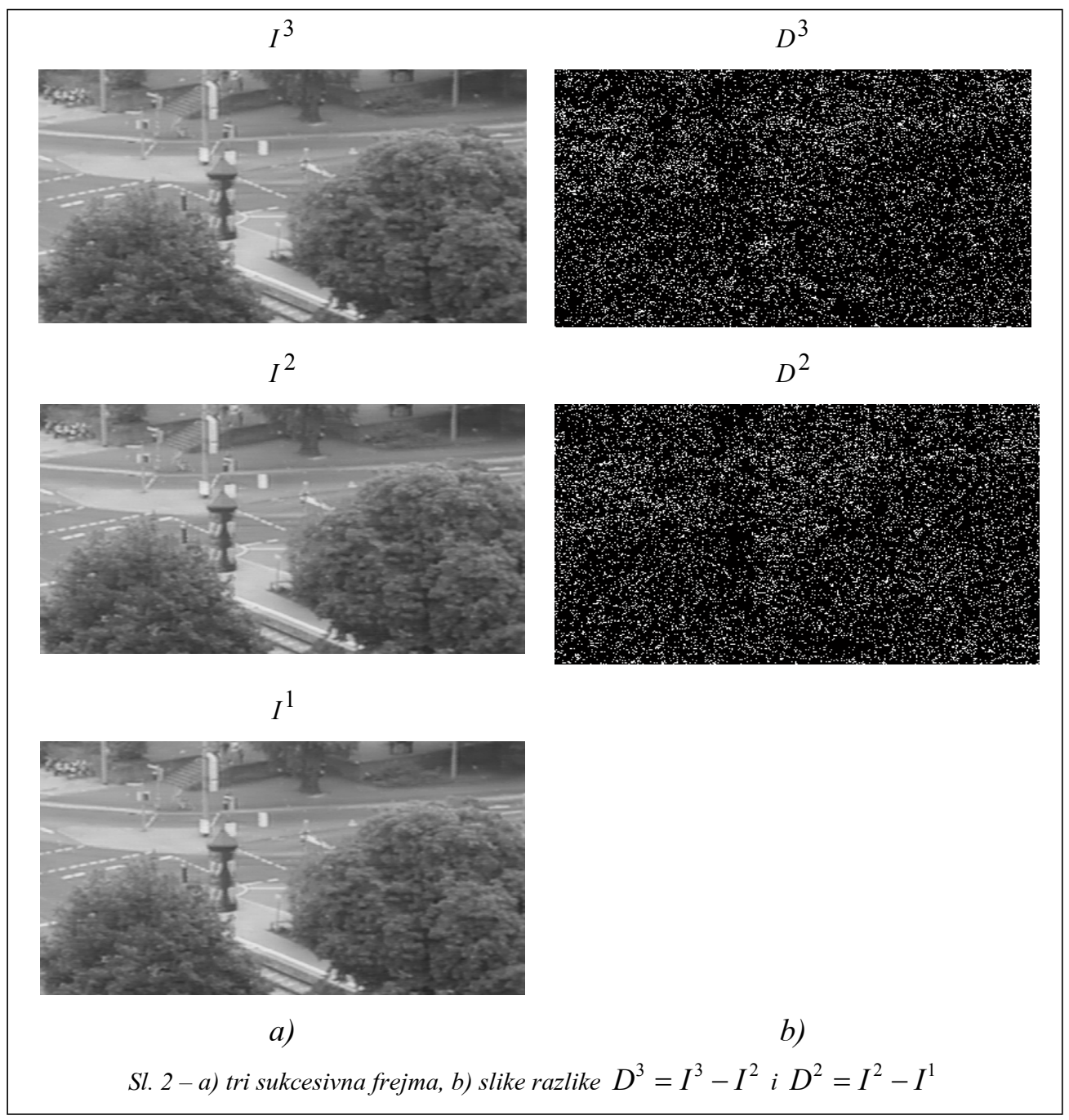

U slučaju da u sekvenci postoje pokretni objekti, iz (1) dobiće se slika razlike sa regionima u kojima je došlo do promene nivoa sivog (regioni od interesa - ROI). Šematski prikaz pokreta prikazan je na slici 4.

Sa slike 4 se vidi da za detekciju regiona u kojem je došlo do promena nije potreban nikakav prag. Oduzimanjem sukcesivnih frejmova detektovan je re- gion u kojem je došlo do promena. Medutim, uzmimo ponovo jednu realnu sekvencu u kojoj postoje pokretni objekti i na ovakav način pokušajmo da detektujemo regione u kojima se nalaze ti objekti. $\mathrm{Na}$ slici 5 prikazana su dva sukcesivna frejma i slika razlike.

Iako se sa slike razlike $5 \mathrm{v}$ može zaključiti da su na ovaj način stvarno detektovani regioni u kojima je došlo do 


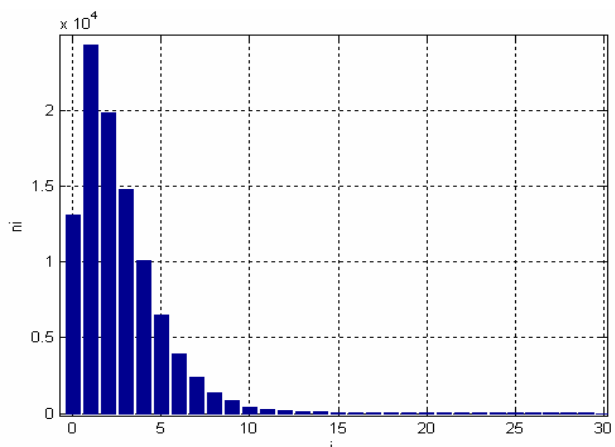

Sl. 3 - Histogram slike razlike $D^{3}$, sa slike $2 b$

promena, sa slike $5 \mathrm{~g}$ vidi se da je, pored ovih regiona, detektovan veliki broj piksela koji ne pripadaju pokretnim objektima. Njihova detekcija je posledica šuma. Oni na slici 5v nisu uočljivi, jer odgovaraju malim nivoima sivog (blizu crnog nivoa). Histogram slike razlike $D^{2}$, sa slike $5 \mathrm{v}$, prikazan je na slici 6 .

Zbog prisustva pokretnih objekata histogram sa slike 6 se proširio u odnosu na histogram sa slike 3 . Histogram na slici 6 prikazan je samo za opseg nivoa sivog u kojem je došlo do promena (od 0 do 155 nivoa sivog).

\section{Detekcija pokreta oduzimanjem slike pozadine od tekućeg frejma}

Označimo sa $B^{n}(x, y)$ intenzitet piksela slike pozadine na poziciji $(x, y)$, u trenutku $t=t_{n}$. Za sada ce se pretpostaviti da je slika pozadine poznata. Detekcija pokreta može se izvršiti na osnovu razlike tekućeg frejma i slike pozadine $[2,4,5,8,9]$ :

$$
\begin{aligned}
& D^{n}(x, y)=\left|I^{n}(x, y)-B^{n}(x, y)\right|, \\
& \forall(x, y) \in[1, N] \times[1, M]
\end{aligned}
$$

Šematski prikaz tekućeg frejma, slike pozadine i slike razlike prikazan je na slici 7.

Sa slike 7 vidi se da za detekciju pokreta nije potreban nikakav prag. Samim oduzimanjem slike pozadine od tekućeg frejma detektovan je čitav pokretni objekat. Međutim, uzmimo ponovo jednu realnu sekvencu u kojoj postoje pokretni objekti i na ovakav način pokušajmo da detektujemo pokret. Postupak je prikazan na slici 8 .

Iako se sa slike razlike $8 \mathrm{v}$ može zaključiti da su na ovaj način stvarno detektovani pikseli kod kojih je došlo do promene nivoa sivog zbog pokretnih objekata, sa slike $8 \mathrm{~g}$ vidimo da je pored njih detektovan i veliki broj piksela koji ne pripadaju pokretnim objektima. Njihova detekcija je posledica šuma. Oni na slici $8 \mathrm{v}$ nisu uočljivi jer odgovaraju malim nivoima sivog (blizu crnog nivoa). Histogram slike razlike $D^{1}$, sa slike $8 \mathrm{v}$, prikazan je na slici 9 .

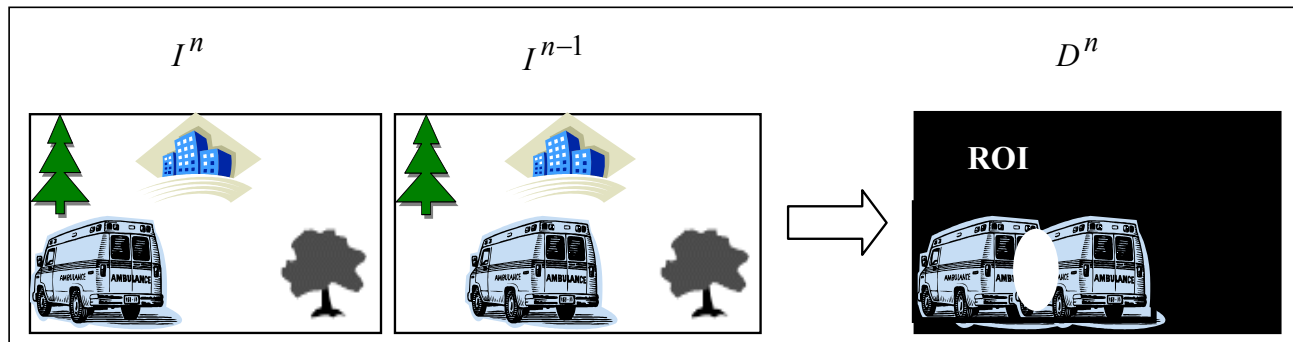

Sl. 4 - Ilustracija oduzimanja sukcesivnih frejmova u kojima postoje pokretni objekti 


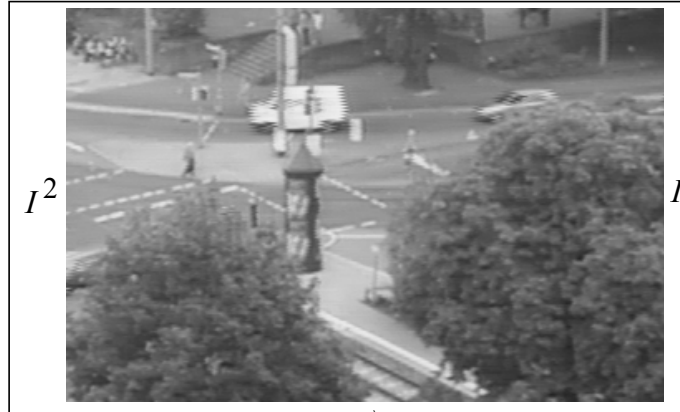

a)

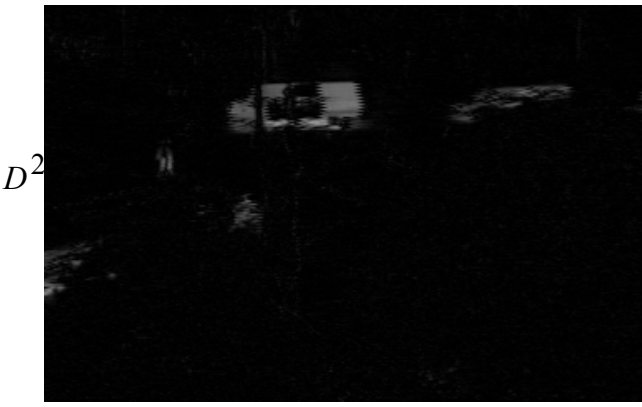

v)

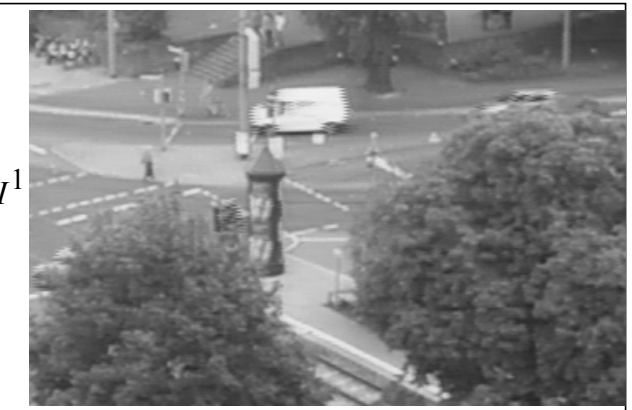

b)

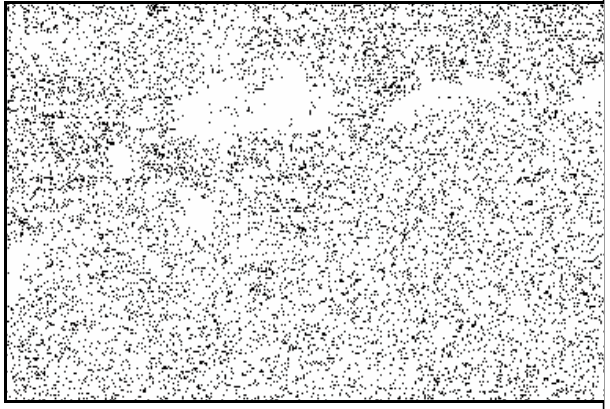

g)

Sl. 5 - Formiranje slike razlike:

a) tekući frejm, b) prethodni frejm, v) slika razlike, g) pikseli kod kojih nije došlo do promene nivoa sivog

Zbog prisustva pokretnih objekata histogram na slici 9 se proširio u odnosu na histogram sa slike 3 . Histogram na slici 9 prikazan je samo za opseg nivoa sivog u kojem je došlo do promena (od 0 do 140 nivoa sivog).

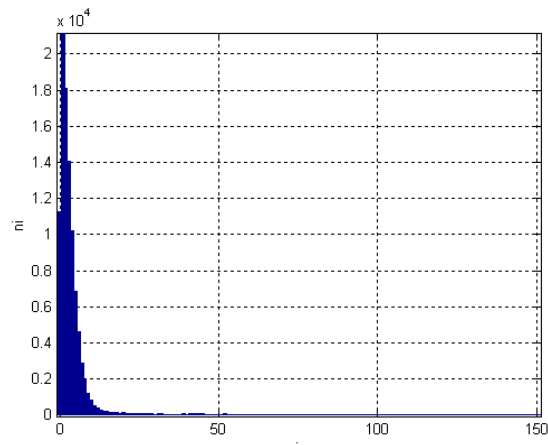

Sl. 6 - Histogram slike razlike $D^{2}$, sa slike $5 v$
Kod oba navedena postupka za detekciju pokreta na slici scene javlja se uticaj šuma. Zbog uticaja šuma, pored detekcije promene nivoa sivog piksela, što je posledica prisustva pokretnih objekata, detektovan je i veliki broj piksela kod kojih je došlo do promene nivoa sivog zbog uticaja šuma. Da bi se eliminisao uticaj šuma i donela odluka o tome kod kojih je piksela došlo do promene nivoa sivog zbog prisustva pokretnih objekata, potrebno je na sliku razlike $D^{n}(x, y)$ primeniti prag $T(T \in[0,255])$. Na taj način dobija se binarna slika $I_{b}^{n}(x, y)$ u kojoj su pikseli klasifikovani u dve klase (pozadina i pokretni piksel), tj:

$$
I_{b}^{n}(x, y)=\left\{\begin{array}{c}
0, D^{n}(x, y) \leq T \\
255, D^{n}(x, y)>T
\end{array}\right.
$$




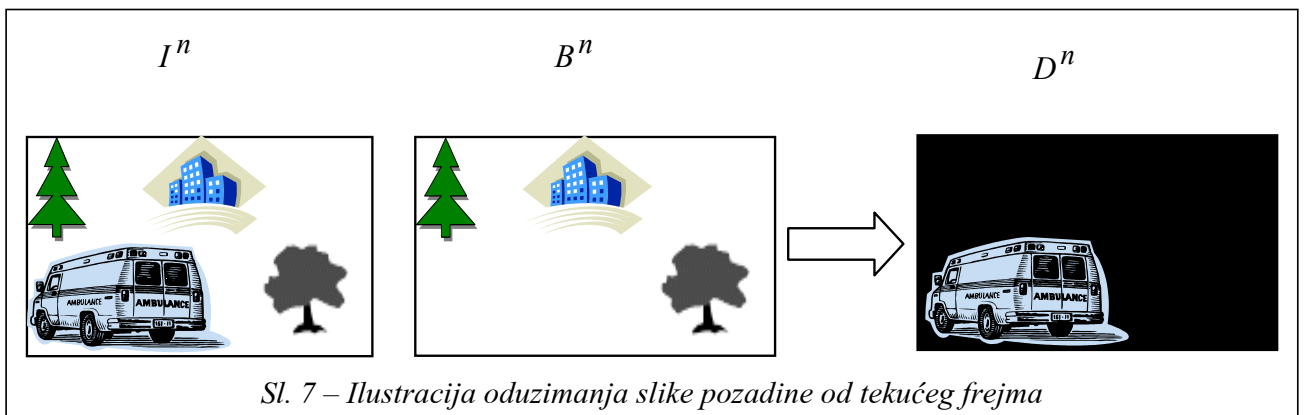

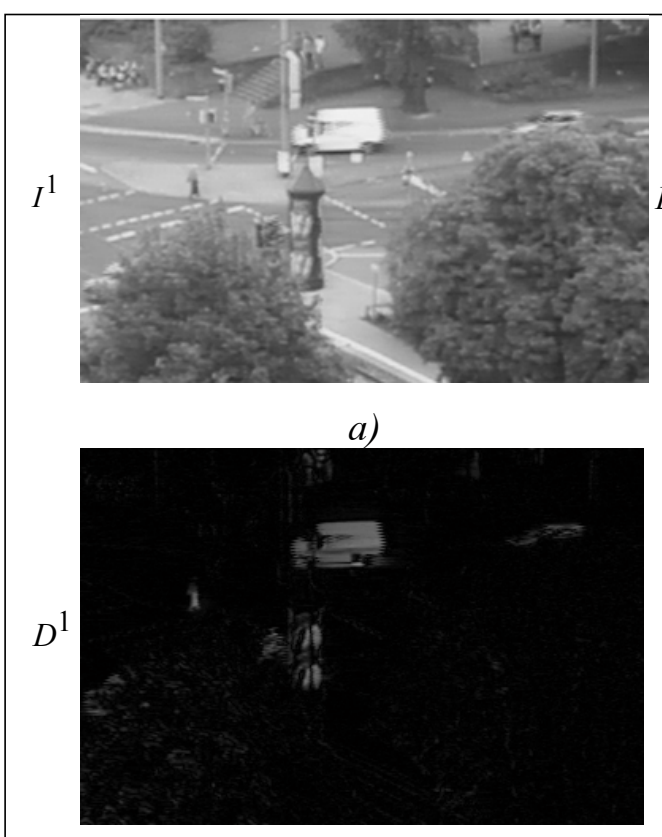

v)

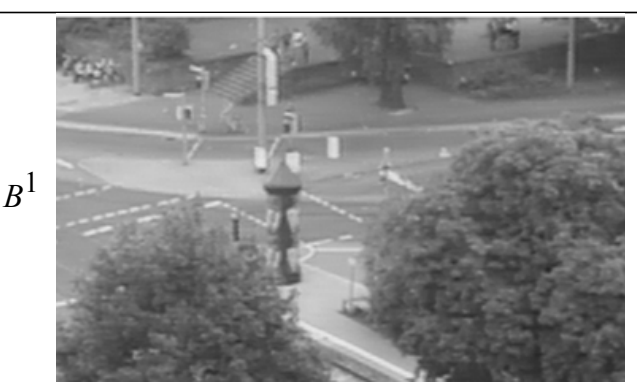

b)

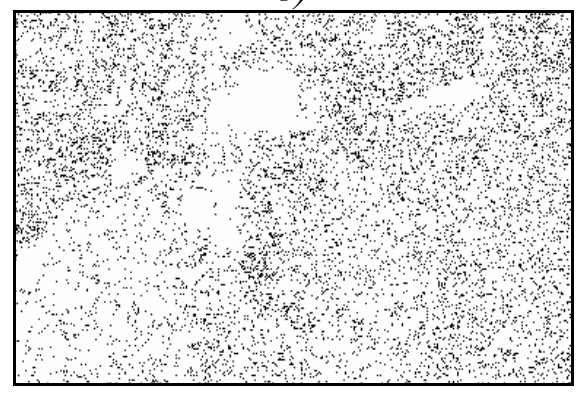

g)

Sl. 8 - Formiranje slike razlike:

a) tekući frejm, b) slika pozadine, v) slika razlike, g) pikseli kod kojih nije došlo do promene nivoa sivog

To znači da je piksel pokretan ako se njegov intenzitet nivoa sivog bitno promenio u tekućem i prethodnom frejmu ili u tekućem frejmu i slici pozadine.

Ako se na slike razlike $5 \mathrm{v}$ i $8 \mathrm{v}$ primeni, na primer, prag $T=40$, dobiće se rezultati koji su prikazani na slici 10 . Izbor metoda određivanja praga detekcije pokreta zahteva dalju analizu.
$\mathrm{Na}$ slikama razlike, posle primene praga detekcije pokreta (slika 10), vidljivi su regioni u kojima je detektovana promena nivoa sivog. Na slici 10 mogu se videti konture pokretnih objekata. Poređenjem slika razlike (slike $5 \mathrm{v}$ i $8 \mathrm{v}$ ) sa binarnim slikama (slika 10) uočljivi su efekti praga, jasnije su izdvojeni regioni promene i dobijena je digitalna slika sa 
dva nivoa sivog (binarna slika). Pored toga, na slici 10 uočljivi su i usamljeni pikseli, čija je detekcija posledica šuma na slikama razlike.

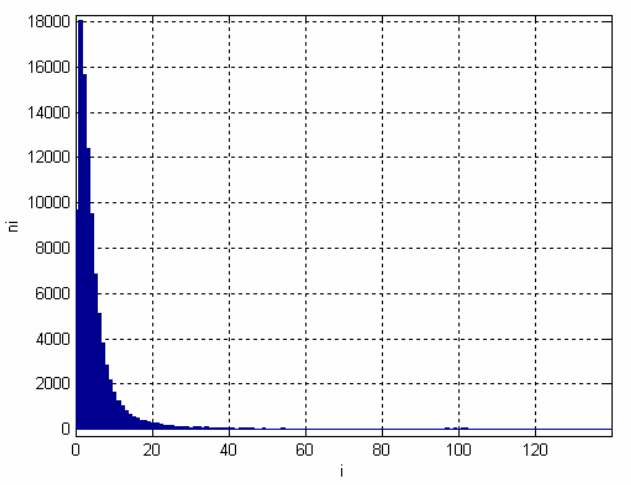

Sl. 9 - Histogram slike razlike $D^{\prime}$, sa slike $8 v$

\section{Kombinovani metod detekcije pokreta na slici scene}

Kombinovani metod detekcije predstavlja spoj tehnika oduzimanja sukcesivnih frejmova i oduzimanja slike pozadine. Osnovna mana kod tehnike oduzimanja pozadine jeste što je osetljiva na situacije kada stacionarni objekti scene počinju da se kreću. Iako će ovi objekti biti detektovani, oni iza sebe ostavljaju ,rupe“ gde se novootkrivena pozadina razlikuje od poznate slike pozadine (slika 11a). Dok se model pozadine prilagodi ovim „rupama“, sam algoritam detekcije određeno vreme generiše lažne objekte. Razlika sukcesivnih frejmova nije osetljiva na pojavu, ,rupa“, ali ovaj algoritam menja oblik pokretnog objekta (slika 11b).

Da bi se izbegli navedeni nedostaci koristi se kombinacija ova dva metoda. Oduzimanje sukcesivnih frejmova koristi se za odredivanje regiona stvarnih pokreta, a oduzimanje slike pozadine za izdvajanje pokretnih objekata. Osim razlike dva sukcesivna frejma, može se koristiti razlika tri ili više sukcesivnih frejmova [7]. Pravilo razlike tri sukcesivna frejma kaže da je piksel na poziciji $(x, y)$ pokretan, ako je:

$$
\left|I^{n}(x, y)-I^{n-1}(x, y)\right|>T \quad \mathrm{i}
$$$$
\left|I^{n}(x, y)-I^{n-2}(x, y)\right|>T
$$

gde je $T$ odgovarajući prag nivoa sivog.

I na ovaj način dobija se binarna slika $I_{b}^{n}(x, y)$ u kojoj su pikseli klasifikovani u dve klase (slika 12b).

Primenom razlike tri sukcesivna frejma eliminisani su neki pokretni pikseli koji su detektovani na osnovu razlike dva sukcesivna frejma, a čija detekcija nije posledica pokreta objekata. Ovi pikseli obuhvaćeni su pravougaonikom na slici $12 \mathrm{v}$.

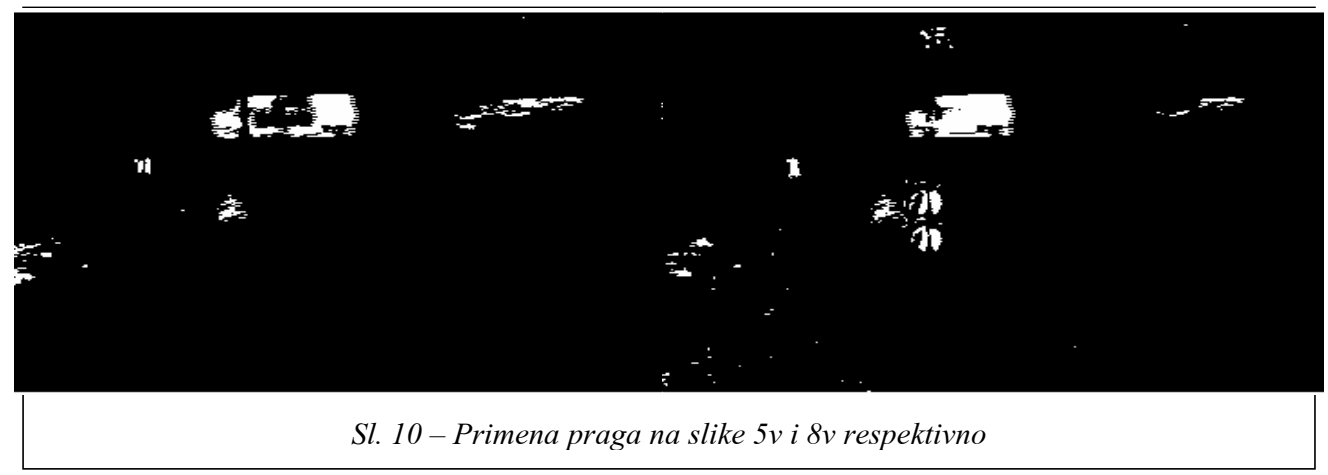




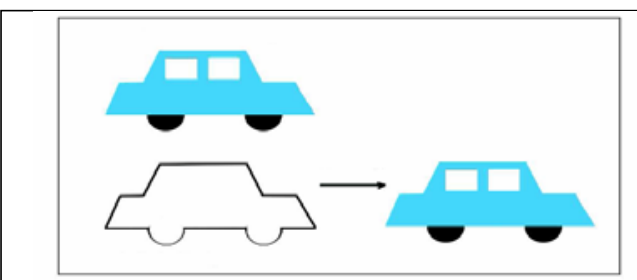

a)

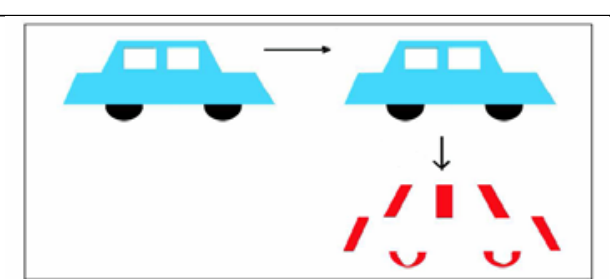

b)

Sl. 11 - a) oduzimanje slike pozadine ostavlja ,rupe“ kada stacionarni objekat počinje da se kreće, b) oduzimanje sukcesivnih frejmova menja oblik pokretnog objekta

Na slici $12 b$ vidi se i da su grupe piksela koje pripadaju jednom objektu prostorno odvojene. Da bi se ove grupe spojile mogu se primeniti morfološke operacije.

\section{Primena morfoloških operacija u detekciji pokreta}

Od morfoloških operacija u detekciji pokreta najčešće se koriste dilatacija i erozi- ja. Operacije dilatacije i erozije sastoje se u interakciji binarne slike i strukturnog elementa kojom se menja oblik objekta. Strukturni element čini grupa piksela koja formira određeni oblik (kvadrat, krst, krug, itd.). Najčešći oblik strukturnog elementa $S$ je kvadrat dimenzija $3 \times 3$ piksela [10].

Dilatacijom binarne slike $I_{b}^{n}(x, y)$ strukturnim elementom $S d$ dobija se bi-

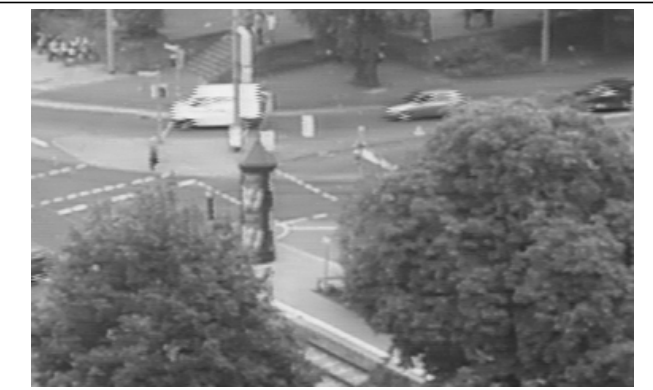

a)
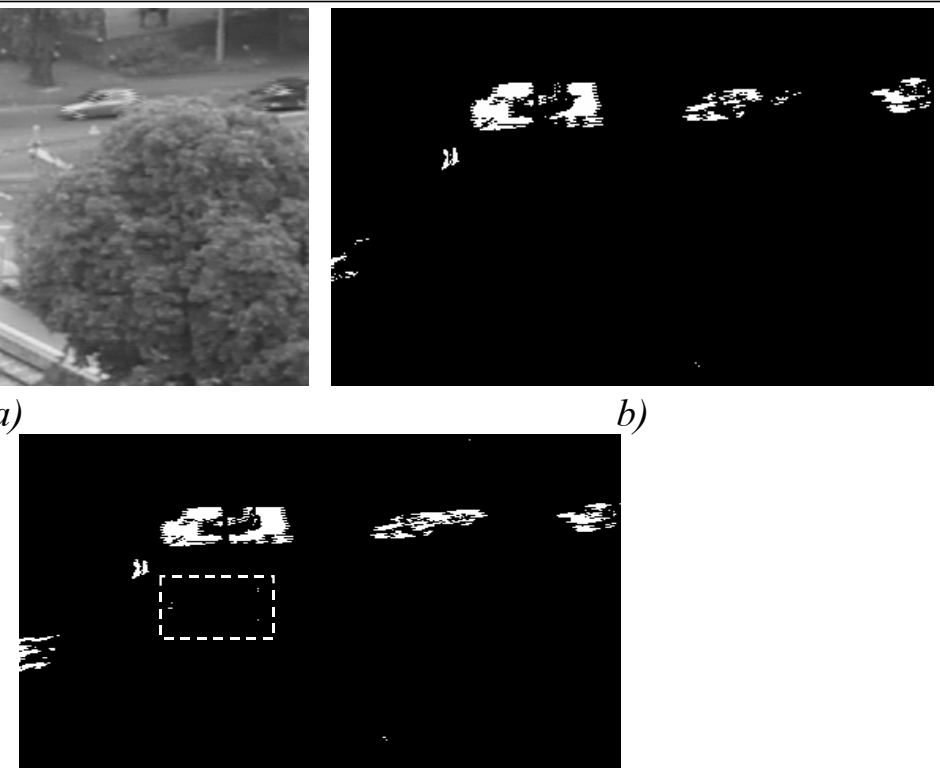

v)

Sl. 12 - a) tekući frejm, b) pokretni pikseli u tekućem frejmu dobijeni na osnovu razlike tri sukcesivna frejma, v) pokretni pikseli u tekućem frejmu dobijeni na osnovu razlike dva sukcesivna frejma 
narna slika $I_{b d}^{n}(x, y)$ koja predstavlja skup takvih tačaka $(x, y)$ da, posle translacije strukturnog elementa $\mathrm{u}$ tačku $(x, y)$, presek skupova $I_{b}^{n}(x, y)$ i $S d$ ne bude prazan skup [10]. Postupak dilatacije može se rekurzivno primenjivati. Sama dilatacija predstavlja operaciju širenja objekta.

Erozijom binarne slike $I_{b d}^{n}(x, y)$ strukturnim elementom $\mathrm{Se}$ dobija se binarna slika $I_{b e}^{n}(x, y)$ koja predstavlja skup takvih tačaka $(x, y)$ da je posle translacije strukturnog elementa $\mathrm{u}$ tačku $(x, y)$, ceo strukturni element $S e$ uključen u $I_{b d}^{n}(x, y)$ [10]. Postupak erozije se, takođe, može rekurzivno primenjivati. Sama erozija predstavlja operaciju sužavanja objekta.

Operacije dilatacije i erozije imaju suprotan efekat, ali nisu inverzne jedna u odnosu na drugu. Ako se nad nekom binarnom slikom prvo izvrši dilatacija strukturnim elementom $S d$, ta binarna slika se više ne može rekonstruisati bilo kakvom naknadnom erozijom. Na slici 13 može se videti šta se dobija nakon primena operacija dilatacije i erozije na binarnu sliku $12 \mathrm{~b}$.

I nakon primena morfoloških operacija pikseli, koji se nalaze u unutrašnjosti uni-

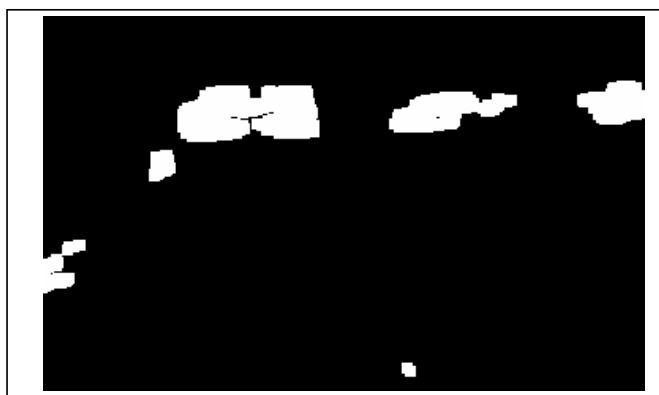

a) formno osvetljenih objekata, neće biti uključeni u skup pokretnih piksela (slika 13b).

\section{Povezanost piksela}

Ako se izvrši grupisanje pokretnih piksela koji pripadaju istom objektu, pikseli iz unutrašnjosti mogu se uključiti oduzimanjem slike pozadine.

Grupisanje pokretnih piksela vrši se na osnovu povezanosti piksela, koja se može ispitivati poređenjem sa četiri susedna piksela ili ispitivanjem sa osam susednih piksela. Tako se dobijaju pojmovi 4-susedstvo i 8-susedstvo, odnosno 4-povezanost i 8-povezanost (slika 14) [10].

U slučaju kada se piksel $A$ poredi sa četiri najbliža susedna piksela, kao na slici 14a, dovoljno je da ima ista svojstva kao jedan od njih, pa da se pridruži odgovarajućoj kategoriji. Takva povezanost se naziva 4-povezanost. U slučaju kada se poređenje vrši sa osam najbližih susednih piksela, kao na slici 14b, dobija se 8-povezanost.

Grupisanjem piksela sa slike $13 \mathrm{~b}$ dobijaju se regioni pokretnih piksela (slika 15). Za dobijanje regiona pokretnih piksela primenjena je 8-povezanost.

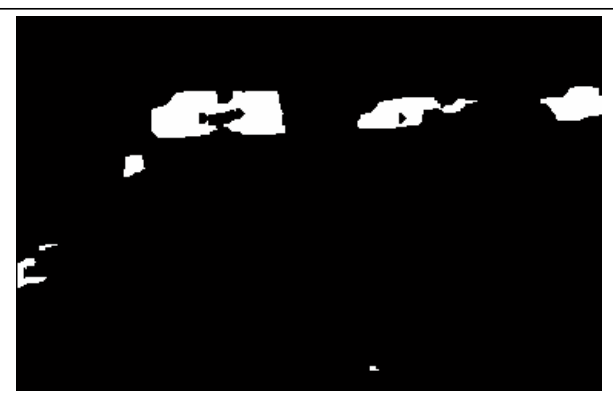

b)

Sl. 13 - a) primena dilatacije na binarnu sliku 12b, b) primena erozije na sliku 13 a 


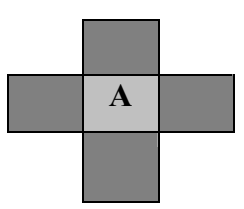

a)

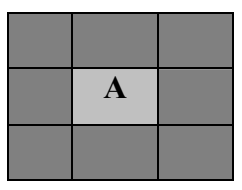

b)
Sl. 14 - Povezanost piksela:

a) 4-susedstvo, b) 8-susedstvo

Regioni pokretnih piksela služe da bi se odredili delovi tekućeg frejma u kojima se nalaze pokretni objekti. Delovi tekućeg frejma, u kojima se nalaze pokretni objekti, određeni su na osnovu krajnjih tačaka svakog regiona pokretnih piksela, tj. tako što se svaki region pokretnih piksela obuhvati pravougaonikom minimalnog obima (minimum bounding rectangle) $[4,5]$. Na slici 16 prikazani su delovi tekućeg frejma (slika 12a) u kojima se nalaze pokretni objekti.

Označimo sa $R_{i}^{n}$ deo tekućeg frejma $\mathrm{u}$ kojem se nalazi pokretni objekat. Pokretni objekat $b_{i}^{n}$ biće detektovan ako se uzmu svi pikseli iz $R_{i}^{n}$, čiji se intenzitet bitno razlikuje od modela pozadine, tj.:

$b_{i}^{n}=\left\{(x, y):\left|I^{n}(x, y)-B^{n}(x, y)\right|>T,(x, y) \in R_{i}^{n}\right\}$

Ilustracije radi, na slici 17 obeleženi su regioni u kojima postoje pokretni objekti.

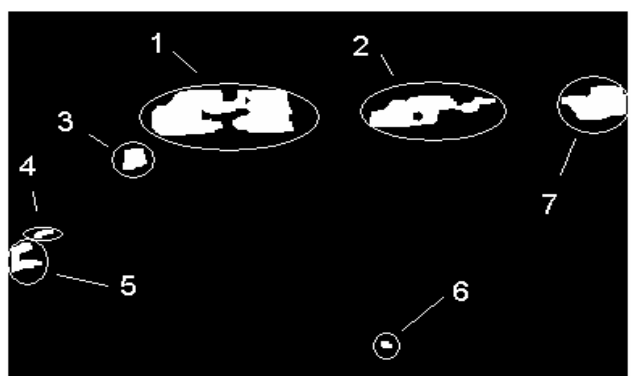

Sl. 15 - Regioni pokretnih piksela sa slike $13 \mathrm{~b}$ (regioni su obeleženi brojevima 1-7)

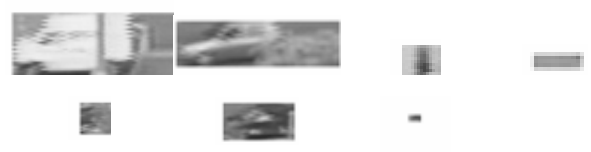

Sl. 16 - Delovi tekućeg frejma (slika 12a) u kojima se nalaze pokretni objekti

Na slici 17 mogu se videti ivice detektovanih objekata (slika 17a) i detektovani pokretni objekti (slika 17b). Detekcija ivica vršena je na osnovu binarne slike koja se dobija pomoću (7) (detekcija prelaza 0-255 i obratno). Iz navedenog primera vidi se da je ovakav način detekcije uspešno detektovao pet pokretnih objekata (četiri automobila i jednog pešaka), ali je i detektovao dva pokretna objekta kojih u stvarnosti nema (lažni alarmi). Ovaj nedostatak se može otkloniti ako se uzmu u razmatranje samo detektovani pokretni objekti, dimenzija većih od unapred zadatih [6].

\section{Izdvajanje pozadine}

$\mathrm{U}$ nekim primenama detekcije pokreta na sceni nije moguće iz same sekvence izdvojiti jedan frejm i proglasiti ga pozadinom. Navedeni problem javlja se ukoliko u sekvenci uvek postoje pokretni objekti (autoput, raskrsnice,...). Zbog toga je potrebno formirati sliku pozadine $B^{n}(x, y)$ iz sekvence frejmova $I^{t}(x, y)$, koja može sadržati pokretne objekte. Kako je za detekciju pokretnih objekata potrebna slika pozadine, prvi korak u detekciji treba da bude izdvajanje pozadine.

Za izdvajanje pozadine može da se koristi srednja vrednost ili medijana određenog broja frejmova [9]: 


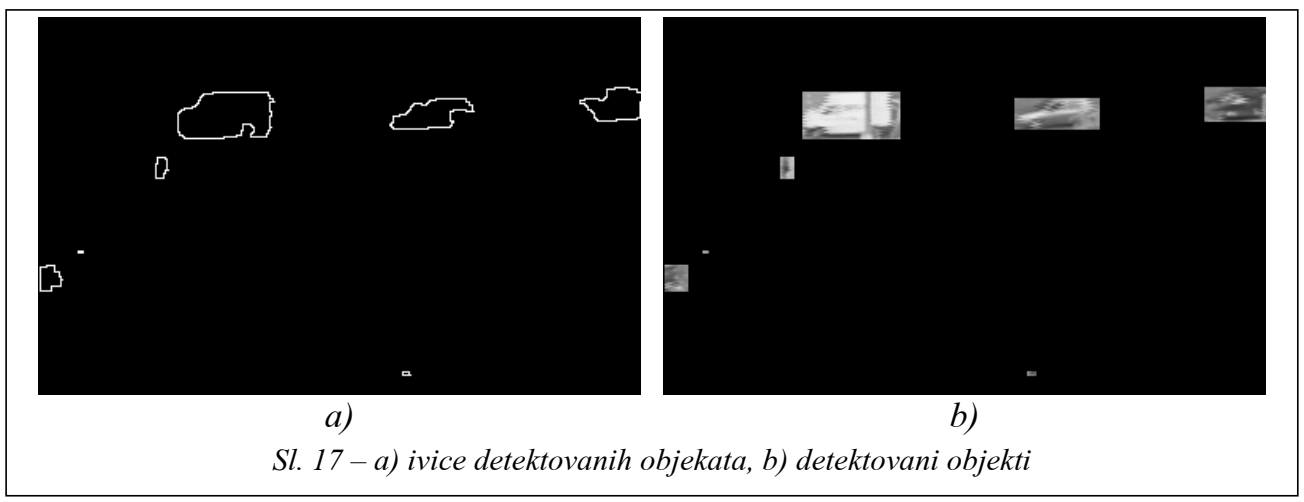

$$
\begin{aligned}
& B^{n}(x, y)=\text { mean }_{t} I^{t}(x, y), \\
& B^{n}(x, y)=\text { med }_{t} I^{t}(x, y)
\end{aligned}
$$

Jedan metod, koji se koristi, daje sli$\mathrm{ku}$ pozadine $\mathrm{u}$ nekoliko iteracija $[3,8]$. Metod polazi od početne slike pozadine koja je jednaka prvom frejmu $B^{0}(x, y)=I^{0}(x, y)$. Da bi se dobila slika pozadine koja odgovara tekućem frejmu, u sukcesivnim frejmovima moraju se detektovati pokretni pikseli, a zatim izdvojiti pozadina na osnovu $[7,8]$ :

$$
B^{n+1}(x, y)=\left\{\begin{array}{l}
\alpha B^{n}(x, y)+(1-\alpha) . \\
I^{n}(x, y),(x, y)-\text { nepokretan } \\
B^{n}(x, y),(x, y)-\text { pokretan }
\end{array}\right.
$$

Od težinskog koeficijenta $\alpha$ zavisi brzina promene. Iz (9) vidi se da do promene vrednosti piksela slike pozadine dolazi ako je piksel klasifikovan kao nepokretan, tj. ako je deo stacionarne pozadine. U suprotnom, pokretni pikseli ,poremetili“ bi sliku pozadine. U ovom radu koristi se koeficijent $\alpha=0,9$, koji je predložen u literaturi $[7,8]$. Primer izdvajanja pozadine na ovakav način prikazan je na slici 18 .

Slika 18a predstavlja početnu (inicijalnu) pozadinu na kojoj postoji više pokretnih objekata. Slike $18 \mathrm{~b}$ i $18 \mathrm{~g}$ su slike 19. i 32. frejma, a slike $18 \mathrm{v}$ i $18 \mathrm{~d}$ su slike na ovakav način izdvajane pozadine nakon 19. i 32. frejma. Sa slika 18v i 18d vidi se da se pokretni objekti postepeno gube iz početne pozadine (beli kamion, pešak, automobil). Takođe, na slici $18 \mathrm{~d}$ vidi se da se u slici pozadine postepeno pojavljuje pešak koji čeka na semaforu.

Da bi se prilagodili promenama scene (dan-noć, promene u osvetljenju, promene uslovljene senkom,...) potrebno je da se vrši ažuriranje pozadine, na osnovu izraza (9). Ažuriranje pozadine može da se vrši nakon svakog frejma, a može i u određenim vremenskim intervalima.

\section{Zaključak}

U ovom radu opisan je jedan pristup koji se može primeniti u detekciji pokreta, za koju se koristila obrada slike razlike, formirane oduzimanjem slike pozadine od tekućeg frejma i oduzimanjem suk- 


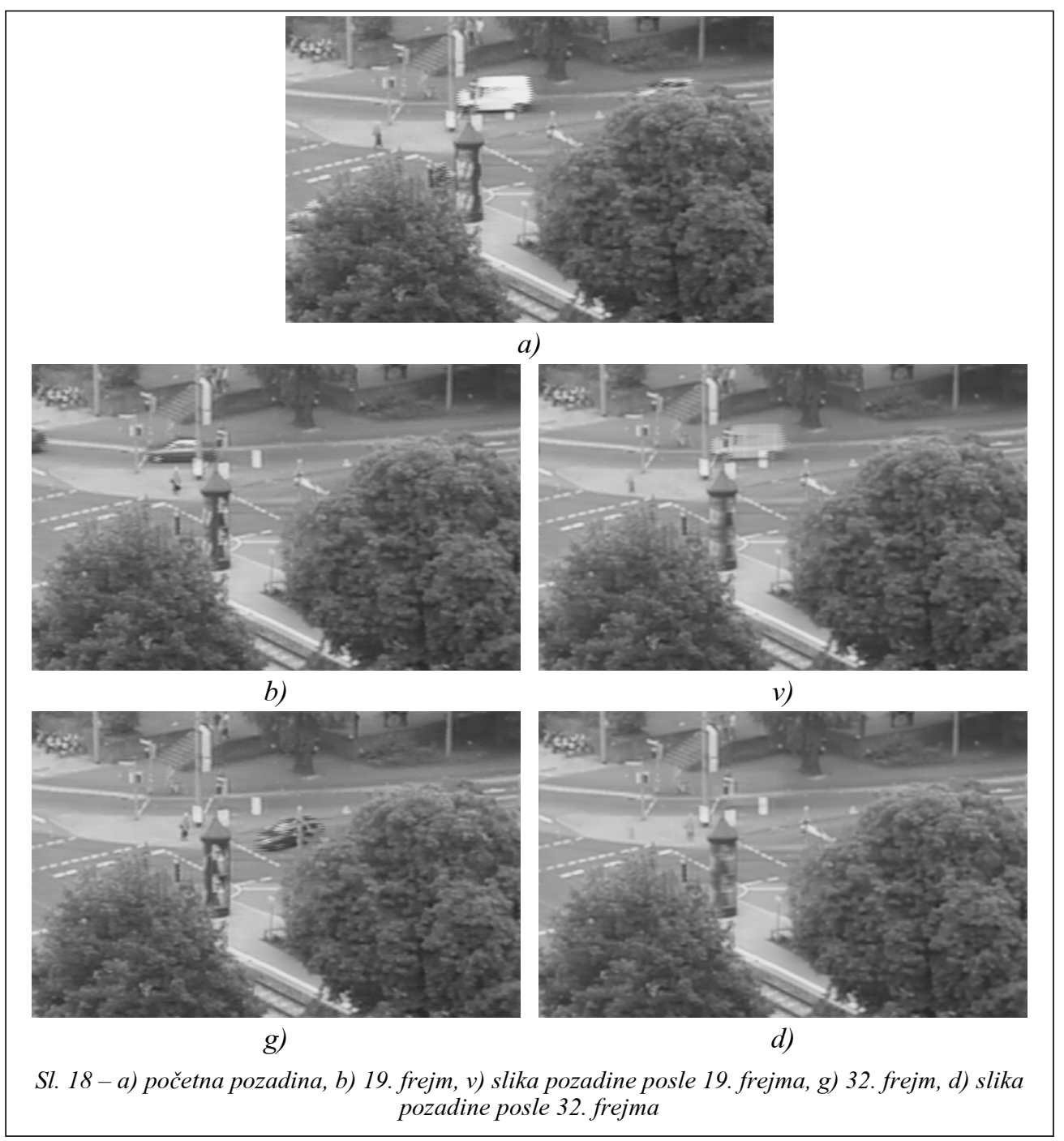

cesivnih frejmova. Zbog nedostataka koji se javljaju ukoliko se koriste tehnike oduzimanja slike pozadine i oduzimanja sukcesivnih frejmova, opisan je i kombinovani metod detekcije. Kako je za detekciju pokreta potrebna slika pozadine, opisan je jedan od postupaka izdvajanja slike pozadine.

Detekcija pokreta praćena je uvođenjem praga detekcije da bi se dobila bi-

narna slika u kojoj su pikseli klasifikovani u dve klase. Izbor metoda određivanja praga detekcije pokreta zahteva dalju analizu.

Pokazano je da se primenom razlike tri sukcesivna frejma mogu eliminisati neki pokretni pikseli koji su detektovani na osnovu razlike dva sukcesivna frejma, a čija detekcija nije posledica pokreta objekata. 
Ovaj pristup detekcije pokreta može se primeniti za kontrolu saobraćaja, detekciju objekata u vazdušnom prostoru, kao i za video nadzor.

Literatura:

[1] Topalović, M.: Televizija, druga knjiga, Višedimenzionalna digitalna obrada video signala, RTS, Beograd, 1993.

[2] Bondžulić, B.; Simić, S.; Zrnić, B.: Jedan pristup detekciji i praćenju sporopokretnih objekata u video sekvenci, Proc. XLVIII ETRAN Conference, Čačak, June 6-10, 2004, Vol. 1.

[3] Bondžulić, B.; Barbarić, Ž.: Prag detekcije pokretnih objekata u video sekvenci, XII Telekomunikacioni forum, Telfor 2004., Beograd.

[4] Foresti, G. L.: A real time system for video surveillance of unattended outdoor environments, IEEE Trans. Circuits Syst., vol. 8, pp. 697-704, Oct. 1998.
[5] Foresti, G. L.: Object Recognition and Tracking for Remote Video Surveillance, IEEE Trans. on Circuits and Systems for Video Technology, Vol. 9, No. 7, Oct. 1999.

[6] Lipton, A.; Fujiyoshi, H.; Patil, R.: Moving target classification and tracking from real-time video, IEEE Workshop on Application of Computer Vision, pp. 19-21, Oct. 1998.

[7] Collins, R.; Lipton, A.; Kanade, T.; Fujiyoshi, H.; Duggins, D.; Tsin, Y.; Tolliver, D.; Hasegawa, O.: A system for video surveillance and monitoring: VSAM final report, Robotics Inst., CMU-RI-TR-00-12, 2000.

[8] Gupte, S.; Masoud, O.; Martin, R.; Papanikolopoulos, N.: Detection and Classification of Vehicles, IEEE Trans. on ITS, Vol. 3, No. 1, March 2002.

[9] Rosin, P. L.; Ellis, T.: Image difference threshold strategies and shadow removal, British Machine Vision Conf. pp. 347-356, 1995.

[10] Popović, M.: Digitalna obrada slike, Rukopis za pripremanje ispita, Beograd, 1998. 